\title{
Estimations and changes of the dominant discharge in Three Gorges Reservoir channel
}

\author{
Guangming $\operatorname{Tan}^{1} \cdot$ Peng Chen ${ }^{1} \cdot$ Jinyun Deng ${ }^{1} \cdot$ Quanxi X $\mathbf{u}^{2} \cdot$ Rouxin Tang ${ }^{1} \cdot$ Zhiyong Feng $^{1} \cdot$ Ying Xiong $^{1}$
}

Received: 8 October 2018 / Accepted: 17 January 2019 / Published online: 25 January 2019

(C) The Author(s) 2019

\begin{abstract}
Dominant discharge is an important parameter reflecting the water inflow process and river channel shape. Since the impoundment and implementation of the Three Gorges Reservoir (TGR), the bed-forming effect of the river channel in the reservoir area has changed significantly. Based on the observed water and sediment data from four hydrological stations in the upper Yangtze River from 1980 to 2017, the dominant discharge of the Zhutuo, Cuntan, Qingxichang, and Wanxian stations before and after the TGR became operational is calculated using the Makayev method, Han Qiwei empirical formula, and flow guarantee rate method. The results show the following: (1) The Makayev method takes both the sediment transport capacity and bed formation duration into account. The physical meaning is clear and the calculation results are relatively reasonable. (2) After the impoundment of the Three Gorges Project (TGP), the dominant discharge of the river decreased in the variable backwater area, while increasing in the perennial backwater area. With the water level rise in front of the dam, the dominant discharge in the variable backwater area remained basically unchanged, while increasing in the perennial backwater area. (3) The dominant discharge in the reservoir area is affected by incoming water processes and the reservoir operation mode, and shows a strong correlation with annual average discharge, flood season average discharge, and flood peak discharge. Before impoundment, the correlation between the dominant discharge and these three parameters was high. After impoundment, the correlation between the dominant discharge and the average flow during flood season was more apparent, further confirming that the bed-forming period of the reservoir is the flood season.
\end{abstract}

Keywords Three Gorges · Reservoir channel · Dominant discharge · Makayev method · Han Qiwei empirical formula . Flow guarantee rate method

\section{Introduction}

Dominant discharge is a discharge rate that reflects the comprehensive actions of bed-forming intensity and multi-year inflow processes (Qian et al. 1987). The complicated variations of natural water and sediment processes shape the different vertical and transverse sections of river channels. Dominant discharge is an important parameter reflecting water and sediment processes as well as channel morphology (Xie 2013). The concept of dominant discharge was originated

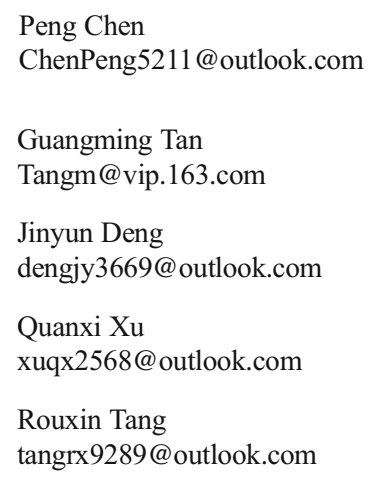

\author{
Zhiyong Feng \\ whu_sid@outlook.com \\ Ying Xiong \\ Xiongying20180901@outlook.com \\ 1 State Key Laboratory of Water Resources and Hydropower \\ Engineering Science, Wuhan University, Wuhan 430072, China \\ 2 Bureau of Hydrology, Yangtze River Water Resources Commission, \\ Wuhan 430010, China
}


from the analysis of the evolution of the Volga River bed by the former Soviet scholar Bigman Lietz J (Xu et al. 2017). Since then, a large number of studies on dominant discharge have been carried out by different scholars at home and abroad for different river types and river regimes. Makayev (Colosimo et al. 1988) considered that the change of river bed is a comprehensive change caused by a complete discharge process. The strength of bed-forming and the duration of each bed-forming stage are two important factors in the calculation of dominant discharge. According to Wolman geomorphic work curve (Wolman and Miller 1960), the geomorphic work curves of the product of frequency and sediment transport rate of different discharge levels are drawn, and the flow corresponding to the peak value of the curve is taken as the dominant discharge. Ferro and Porto (Ferro and Porto 2012) explored the relationship between the dominant discharge and the peak discharge recurrence period of natural rivers in southern Italy. Hadadin (Hadadin 2017) studied the bankfull discharge in the Yazoo River Basin from the perspective of hydraulic geometry. In the Yellow River Basin, Ji Zuwen (Ji et al. 1994) proposed a comprehensive water and sediment frequency method to calculate the dominant discharge according to the characteristics of the Yellow River. Chen Xujian (Chen et al. 2007) adopted Han Qiwei empirical formula to calculate the variation of dominant discharge in the lower Yellow River and its effect on channel shrinkage. Sun Dongpo (Sun et al. 2013) put forward a method for determining the dominant discharge suitable for the variation characteristics of water and sediment in the lower Yellow River basin based on the water-sediment relationship coefficient method. In the Yangtze River Basin, Yan Jinbo (Yan et al. 2014) studied the variation of dominant discharge in the downstream of the Three Gorges Reservoir (TGR) based on the analysis of hydrological and sediment data in Yichang before and after the impoundment of the TGR. Chu Wanqiang (Chu et al. 2015) and Xu Lingling (Xu et al. 2017) calculated the dominant discharge of Chongqing main city and Zhenjiang lower reaches of the Yangtze River, respectively. Zhang Wei (Zhang et al. 2018) used different methods to analyze the variation characteristics of dominant discharge in the middle and lower reaches of the Yangtze River before and after the operation of the TGR.

At present, the commonly used methods for calculating dominant discharge in China and abroad are the Makayev

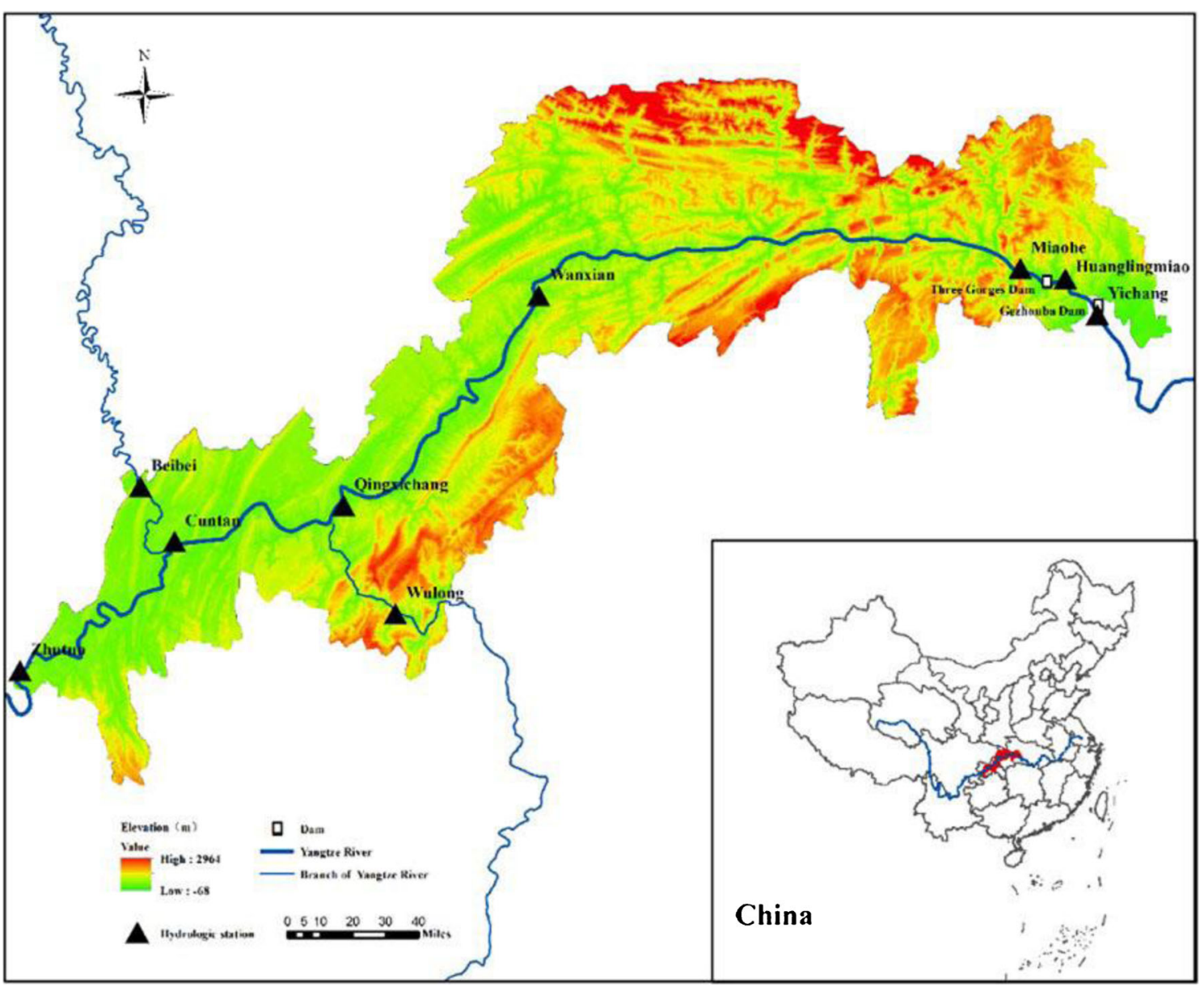

Fig. 1 Sketch map of Zhutuo to dam reach in Three Gorges Reservoir Area 

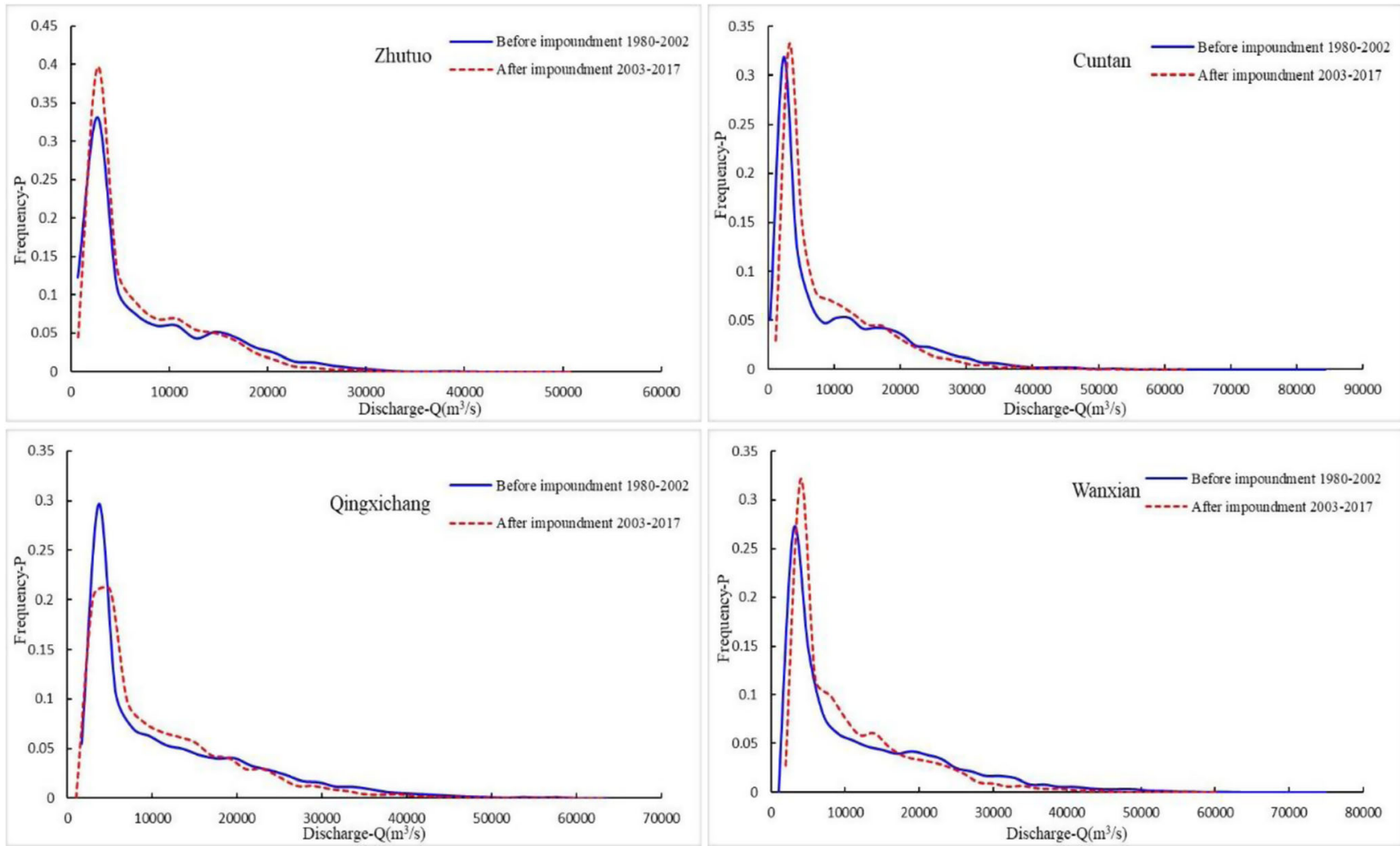

Fig. 2 Distribution of discharge frequency at different levels before and after impoundment of TGR

method, bankfull discharge method, Han Qiwei empirical formula, and flow guarantee rate method. Since related research is currently focused primarily on alluvial rivers, further study is still needed to explore which of these methods is suitable for determining the bed-forming characteristics of reservoir channels. There are many similarities and differences between the bed-forming processes of reservoirs and alluvial channels. Similarities include the fact that both processes form a relatively balanced channel and shore beach through repeated erosion and siltation associated with particular incoming water and sediment processes as well as boundary conditions. The difference is that the relationship between water level and discharge corresponds to the relative channel formed by the alluvial channel. The annual scouring and silting variations are small, and the bed-forming effect is year-round, although it is strongest when there is a large discharge. The water level and discharge in reservoirs do not correspond to the relative channel, and the water levels in front of dams are artificially controlled. The bed-forming action of reservoirs is not only affected by the processes of water and sediment but it is also closely related to the reservoir operation mode. For the alluvial channel, as well as the reservoir in front of dam, the water level remains basically unchanged and the entire year is the bed-forming period. As for the annual regulation reservoir of the Three Gorges, not only will the sediment in the non-bed-forming period be washed away by the large discharge during the bed-forming period but the sediment in the small discharge during the bedforming period will also be washed away. In this way, the balance of the reservoir's vertical section reaches the so-called scouring balance, which differs from the alternate balance resulting from scouring and silting found in alluvial rivers. Therefore, the bed-forming period of the reservoir should be the effective sediment discharge period (i.e., the main flood period) during the flood season, and the corresponding water
Table 1 Water surface gradient corresponding to different discharge grades before impoundment $10^{-4}$

\begin{tabular}{lllllll}
\hline Reach & \multicolumn{7}{l}{ Discharge grades } \\
\cline { 2 - 7 } & 5000 & 10,000 & 20,000 & 30,000 & 40,000 & 50,000 \\
\hline Wanxian to Qingxichang & 1.93 & 1.83 & 1.64 & 1.43 & 1.37 & 1.28 \\
Qingxichang to Cuntan & 0.99 & 1.16 & 1.85 & 2.28 & 2.61 & 2.90 \\
Cuntan to Chongqing & 1.97 & 1.93 & 2.23 & 1.81 & 2.16 & 1.7 \\
Chongqing to Zhutuo & 2.15 & 1.87 & 2.32 & 1.96 & 2.27 & 2.43 \\
\hline
\end{tabular}


Table 2 Water surface gradient corresponding to different discharge grades when the water level in front of the dam is $135 \mathrm{~m}$ $10^{-4}$

\begin{tabular}{lllllll}
\hline Reach & \multicolumn{7}{l}{ Discharge grades } \\
\cline { 2 - 7 } & 5000 & 10,000 & 20,000 & 30,000 & 40,000 & 50,000 \\
\hline Wanxian to Qingxichang & 0.03 & 0.04 & 0.08 & 0.26 & 0.37 & 0.42 \\
Qingxichang to Cuntan & 1.19 & 1.3 & 1.54 & 1.97 & 2.36 & 2.68 \\
Cuntan to Chongqing & 1.21 & 1.23 & 1.29 & 1.32 & 1.43 & 1.61 \\
Chongqing to Zhutuo & 2.08 & 1.76 & 2.24 & 1.86 & 2.14 & 2.32 \\
\hline
\end{tabular}

volume should be the volume during the sediment discharge period (Han and He 1993).

The bankfull discharge method is suitable for the impact reach of a wide, shallow channel and wide floodplain. Since the upper reaches of the Yangtze River reservoir feature a large ratio drop, the channel section is mainly a V-shaped gorge, and the relationship between the lip elevation and the water level and discharge is not easy to accurately calibrate, the author does not consider this calculation method. In this study, the Makayev method, Han Qiwei empirical formula, and flow guarantee rate method will be used to calculate the dominant discharge in the reservoir channel before and after the TGR became operational. The applicability and accuracy of the three methods are examined and compared. A relatively reasonable method is adopted to calculate the dominant discharge rates in the TGR channel since 1980, and the variation characteristics and influential factors of the dominant charge are analyzed.

\section{Research area methods}

\section{Overview of research area}

The spatial scope of this study extended from the Zhutuo station to the site of the TGR dam, a distance of approximately $760 \mathrm{~km}$. There are hydrological stations in the main stream, including Zhutuo, Cuntan, Qingxichang, Wanxian, and Miaohe. The tributaries of the Jialing River contain the Beibei hydrological station, and the tributaries of the Wujiang River contain the Wulong hydrological station (Fig. 1). Following the impoundment and implementation of the TGR, the processes of incoming water and sediment changed noticeably. The annual average runoff decreased, the proportion of annual runoff occurring during the flood and main flood seasons decreased, and the runoff during the dry season increased. The incoming sediment decreased significantly, and the proportion of sediment from the main flood season that contributed to the annual incoming sediment increased; that is, the incoming sediment now tends to be more concentrated during the main flood season (Huang 2016).

From June 2003 to September 2006, the Three Gorges Project (TGP) was in the cofferdam storage period. The water level in front of the dam ran at $135 \mathrm{~m}$ in the flood season and $139 \mathrm{~m}$ in the dry season. The variable backwater area ranged from Fengdu to Lidu, a distance of approximately $64 \mathrm{~km}$. From October 2006 to September 2008, the TGP was in the initial operation period. The water level in front of the dam was operated at $144-145 \mathrm{~m}$ in the flood season and $156 \mathrm{~m}$ in the dry season. The variable backwater area extended from Lidu to Tongluo Gorge, a distance of approximately $95 \mathrm{~km}$. October 2008 to October 2010 was the experimental storage period; the normal storage period began after October 2010. The water level in front of the dam currently runs at $145 \mathrm{~m}$ in the flood season and $175 \mathrm{~m}$ in the dry season, with the variable backwater area stretching from Lidu to Jiangjin, a distance of approximately $183 \mathrm{~km}$. Since the variable backwater area is essentially in a state comparable to that of a natural river under the condition of a flood control-limited water level during flood season, its bedforming period can be calculated using methods for evaluating alluvial channels. Therefore, before the TGR became operational in 2003, the upper reaches of the Yangtze River were effectively an alluvial channel, and the entire year was the bedforming period. After the TGR became operational, the bed-
Table 3 Water surface gradient corresponding to different discharge grades when the water level in front of the dam is $145 \mathrm{~m}$ $10^{-4}$

\begin{tabular}{lllllll}
\hline Reach & \multicolumn{7}{l}{ Discharge grades } \\
\cline { 2 - 7 } & 5000 & 10,000 & 20,000 & 30,000 & 40,000 & 50,000 \\
\hline Wanxian to Qingxichang & 0.01 & 0.02 & 0.03 & 0.12 & 0.18 & 0.21 \\
Qingxichang to Cuntan & 0.03 & 0.05 & 0.06 & 0.09 & 1.2 & 1.28 \\
Cuntan to Chongqing & 1.16 & 1.18 & 1.23 & 1.26 & 1.32 & 1.45 \\
Chongqing to Zhutuo & 1.97 & 1.66 & 2.12 & 1.79 & 2.01 & 2.19 \\
\hline
\end{tabular}



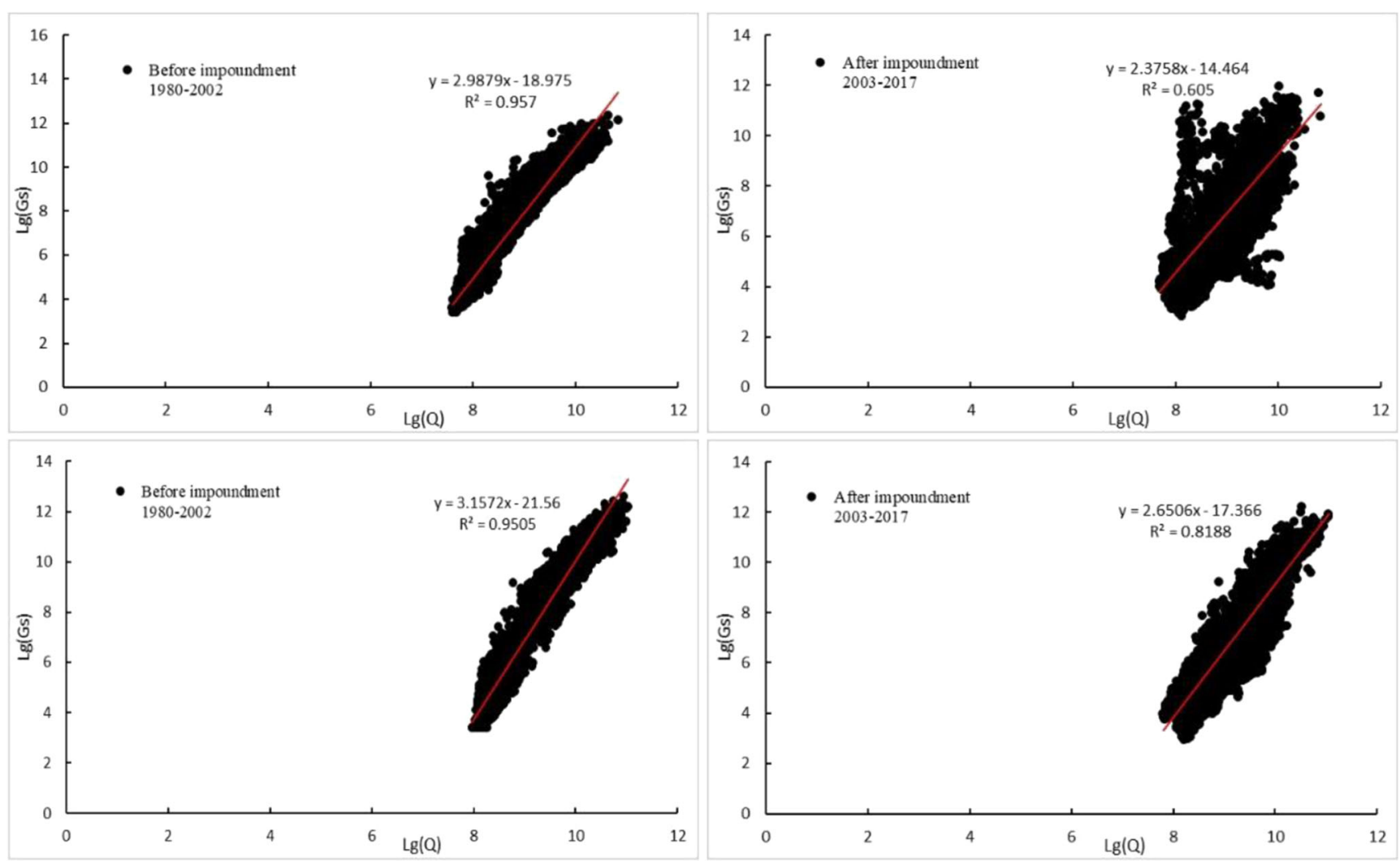

Fig. 3 Relationship between discharge and sediment transport rate at Zhutuo and Cuntan Station before and after impoundment of the TGR

forming period of the channel in the variable backwater area was still the entire year, while the bed-forming period of the channel in the perennial backwater area could be regarded as the main flood period. During the main flood season, from July to September, the TGR basically operates under the restricted water level of flood control. Thus, it can be assumed that the dominant discharge in the reservoir channel is not affected by the water level in front of the dam.

\section{Data and methods}

Owing to Miaohe Hydrological Station is too close to the dam site, the instability of its hydraulic conditions makes it unsuitable to be the representative station of dominant discharge. Thus, this study analyzed the observed 1980 to 2017 hydrological and sediment data from the Zhutuo, Cuntan, Qingxichang, and Wanxian hydrological stations. The year 2003 was taken as the water storage boundary time of the TGR, and 2006 was recognized as the dividing time between flood-limited water levels of $135 \mathrm{~m}$ and $145 \mathrm{~m}$. This research investigated variations of the dominant discharge in the TGR reservoir channel before and after impoundment as well as during periods when the water level in front of the dam rose. The Makayev method, Han Qiwei empirical formula, and flow guarantee rate method were used to calculate the dominant discharge in the TGR reservoir channel. The applicability and accuracy of the three methods were compared and analyzed, and a relatively reasonable method was selected to study the variation characteristics and influential factors of the dominant discharge in the reservoir channel.

\section{Calculation methods}

\section{Makayev method}

The Makayev method maintains that the magnitude of the bed-forming effect for a given discharge is related not only to the sediment transport capacity of the discharge but also to the duration of the discharge. The sediment transport capacity can be considered to be proportional to the product of the $m^{\text {th }}$ power of discharge $Q$ and the specific drop $J$. The duration of the discharge can be expressed by the frequency $P$ of the discharge occurrence. Therefore, when the product $Q^{m} J P$ is at its maximum, the corresponding discharge has the greatest effect on the bed-forming $G$, and this discharge is the required dominant discharge (Xie 2013). The specific calculation methods follow:

(1) Plot the $Q-\mathrm{G}$ relationship curve, where $m$ is the index, which can be determined using the measured data. That is, the Gs- $Q$ relationship curve is plotted using double- 

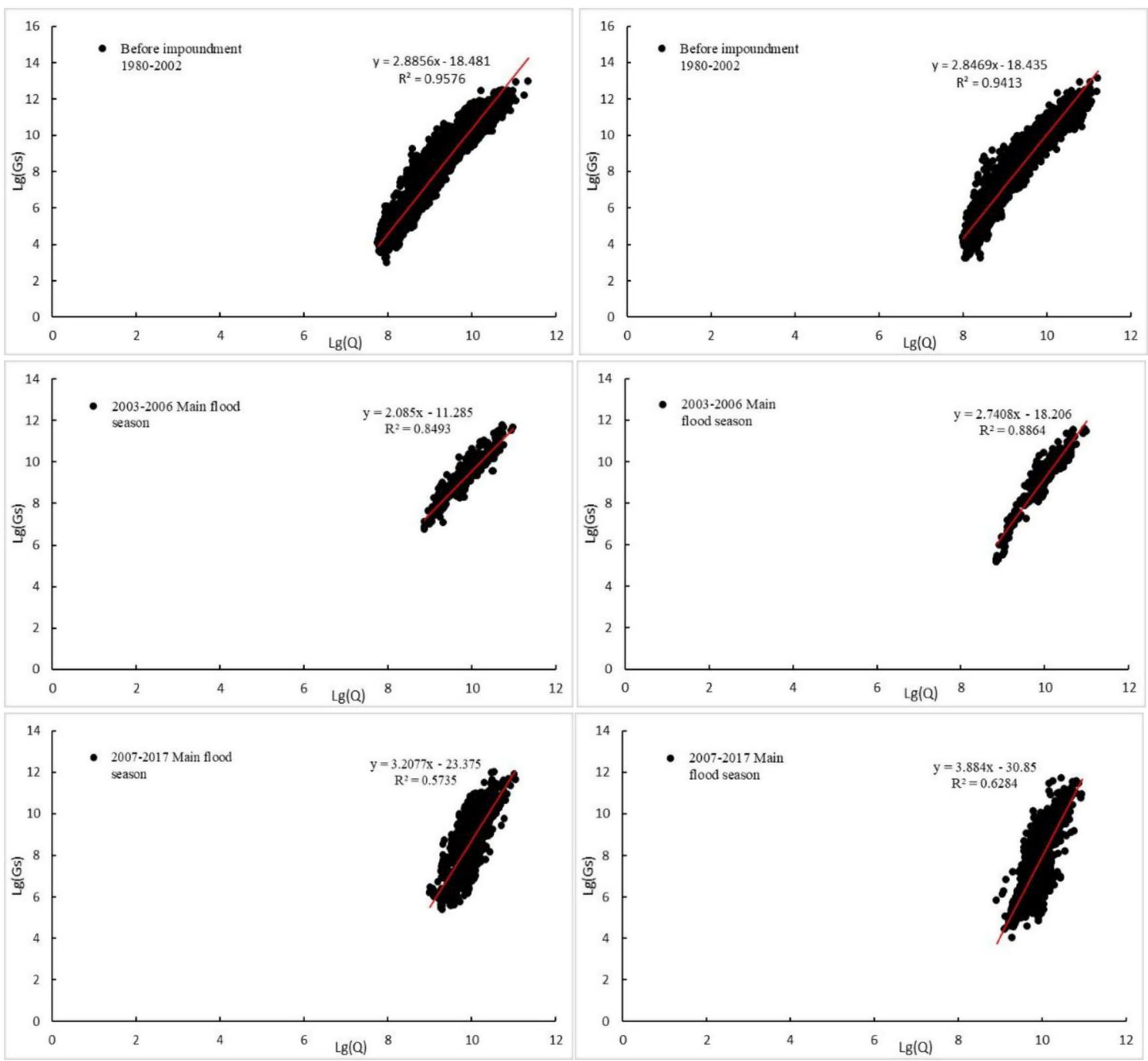

Fig. 4 Relationship between discharge and sediment transport rate at Qingxichang and Wanxian Station before and after impoundment of the TGR as well as the water level in front of the dam is $135 \mathrm{~m}$ and $145 \mathrm{~m}$ respectively

logarithmic coordinates. Gs is the measured sediment transport rate corresponding to $Q ; m$ is the slope of the curve.

Table 4 Parameter (m) under different conditions

\begin{tabular}{llll}
\hline Hydrologic station & \multicolumn{3}{l}{ Parameter $(\mathrm{m})$} \\
\cline { 2 - 4 } & Before impoundment & $135 \mathrm{~m}$ & $145 \mathrm{~m}$ \\
\hline Wanxian & 2.85 & 2.74 & 3.88 \\
Qingxichang & 3.16 & 2.09 & 3.21 \\
Cuntan & 2.89 & 2.65 & 2.65 \\
Zhutuo & 2.99 & 2.38 & 2.38 \\
\hline
\end{tabular}

(2) The maximum $G$ is determined from the plot; the discharge $Q$ corresponding to this maximum value is the required dominant discharge. Analysis of the measured data showed that there are basically two large peaks in the $Q-G$ curve. The discharge corresponding to the first peak is called the first dominant discharge, and the discharge corresponding to the second peak is called the second dominant discharge. Usually, what we call the dominant discharge refers to the first dominant discharge. The main steps follow:

(1) The measured discharge during the bed-forming period is classified using an interval of $2000 \mathrm{~m}^{3} / \mathrm{s}$, and the discharge occurrence frequency is calculated (Fig. 2). 

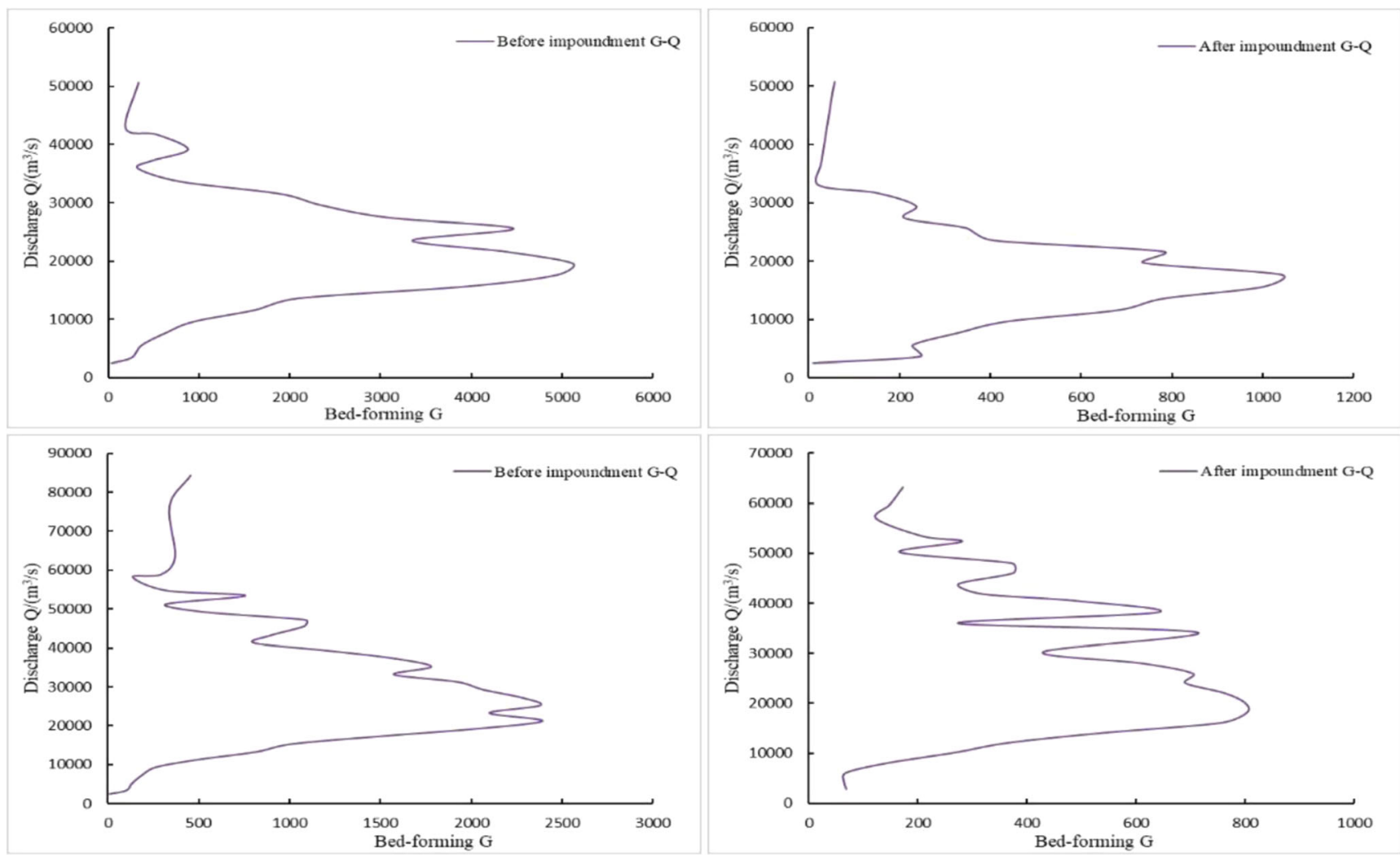

Fig. 5 Relationship between discharge and bed-forming at Zhutuo and Cuntan Station before and after impoundment of the TGR

(2) The water surface gradient is computed by dividing the elevation difference along the river direction by the length of the corresponding reach, and its values at different flow stages are shown in Tables 1, 2 and 3.

(3) From the measured data, the parameters of $135 \mathrm{~m}$ and $145 \mathrm{~m}$ before and after impoundment are determined (Figs. 3, 4 and Table 4).

(4) According to the theory of Makayev method, the dominant discharge refers to the discharge corresponding to the maximum effect of bed-forming, besides, the first dominant discharge is smaller than the second dominant discharge. Therefore, when the effect of bed-forming reaches the maximum and the second maximum, the corresponding discharge is the dominant discharge, among them, the larger discharge is the second dominant discharge, that is the "first peak"; the smaller discharge is the first dominant discharge, that is the "second peak." Thus, from the results of the $Q-G$ relationship curves (Figs. 5 and 6), it was determined that the first dominant discharges at Zhutuo and Cuntan in the upstream variable backwater areas before and after impoundment of the TGP were $19,600 \mathrm{~m}^{3} / \mathrm{s}$ and $17680 \mathrm{~m}^{3} / \mathrm{s}$ and $21,200 \mathrm{~m}^{3} / \mathrm{s}$ and $18130 \mathrm{~m}^{3} / \mathrm{s}$, respectively. The first dominant discharges at Qingxichang and Wanxian in the perennial backwater areas before and after impoundment of the reservoir, as well as when the water levels were
$135 \mathrm{~m}$ and $145 \mathrm{~m}$, were $20,590 \mathrm{~m}^{3} / \mathrm{s}, 26150 \mathrm{~m}^{3} / \mathrm{s}$, and $31980 \mathrm{~m}^{3} / \mathrm{s}$ and $23,910 \mathrm{~m}^{3} / \mathrm{s}, 34960 \mathrm{~m}^{3} / \mathrm{s}$, and $38900 \mathrm{~m}^{3} / \mathrm{s}$, respectively. The second dominant discharges at Zhutuo and Cuntan in the upstream variable backwater areas before and after impoundment of the TGP were $25,640 \mathrm{~m}^{3} / \mathrm{s}$ and $21630 \mathrm{~m}^{3} / \mathrm{s}$ and $27,180 \mathrm{~m}^{3} / \mathrm{s}$ and $26030 \mathrm{~m}^{3} / \mathrm{s}$, respectively. The second dominant discharges at Qingxichang and Wanxian in the perennial backwater areas before and after impoundment of the reservoir, as well as when the water levels were $135 \mathrm{~m}$ and $145 \mathrm{~m}$, were $30,600 \mathrm{~m}^{3} / \mathrm{s}, 34210 \mathrm{~m}^{3} / \mathrm{s}$, and $39540 \mathrm{~m}^{3} / \mathrm{s}$ and $33,960 \mathrm{~m}^{3} / \mathrm{s}, 41150 \mathrm{~m}^{3} / \mathrm{s}$, and $44900 \mathrm{~m}^{3} /$ $\mathrm{s}$, respectively (Tables 5 and 6).

\section{Han Qiwei empirical formula}

The method proposed by Han Qiwei for calculating the first and second dominant discharges can be directly calculated from the measured data of the water and sediment process (Han and He 1993). From these data, the first dominant discharge refers to a particular constant discharge capable of transporting all incoming sediment and causing the reach to achieve longitudinal equilibrium for certain discharge and sediment transport processes and riverbed slope conditions. 

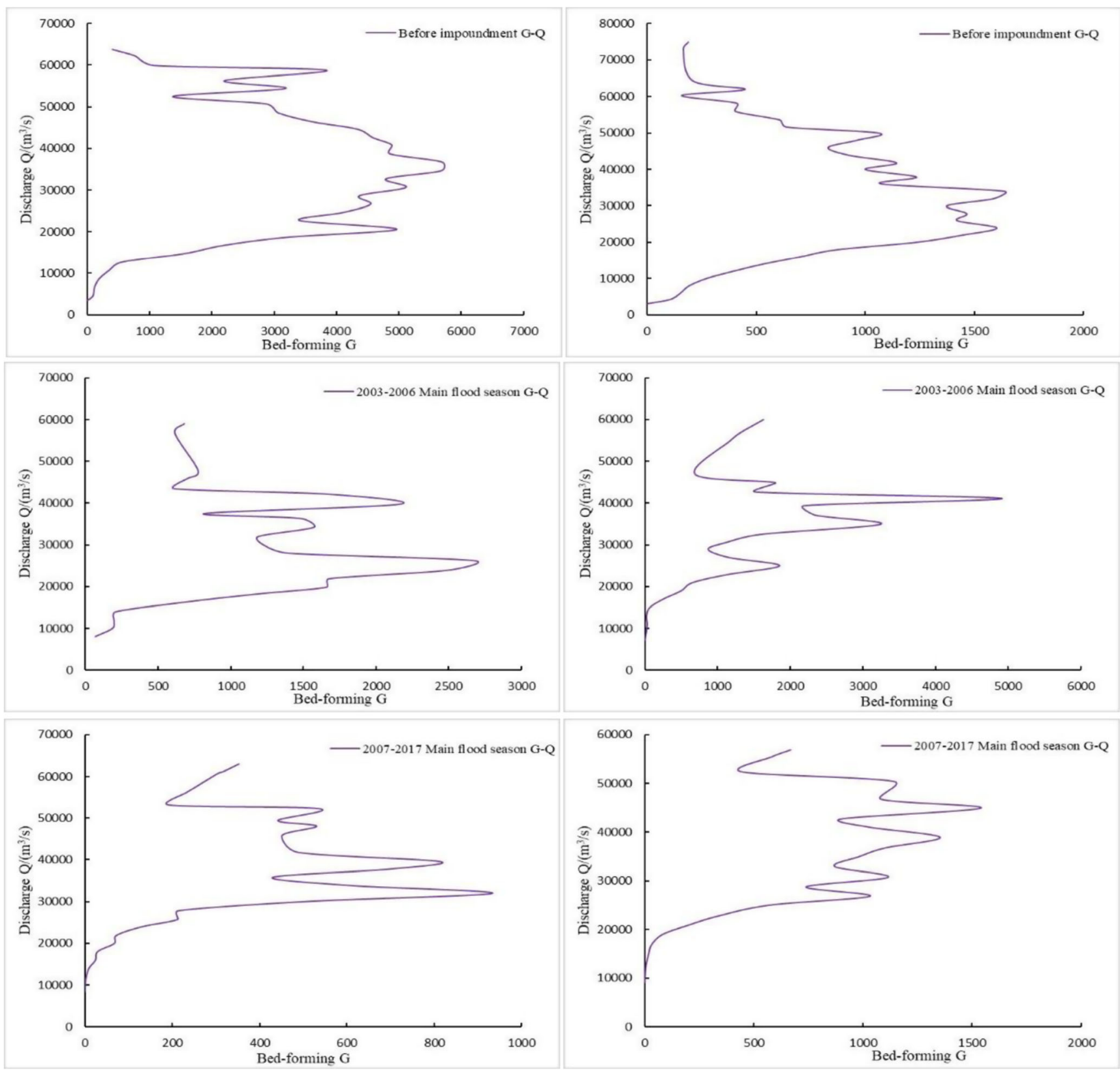

Fig. 6 Relationship between discharge and bed-forming at Qingxichang and Wanxian Station before and after impoundment of the TGR as well as the water level in front of the dam is $135 \mathrm{~m}$ and $145 \mathrm{~m}$ respectively

The first dominant discharge is slightly larger than the annual average discharge, which is equivalent to the discharge corresponding to the level of flat and shallow shoals in a reach with shallow and deep channels. The first dominant discharge determines the size of the deep channel section, the longitudinal ratio drop, and the bending shape of the channel, reflecting the longitudinal equilibrium sediment transport capacity of a certain discharge process in the channel. The formula for calculating the first dominant discharge is:

$Q_{1}=\left[\sum Q_{i}^{1+\alpha} P_{i}\right]^{\frac{1}{1+\alpha}}=\left[\sum Q_{i}^{\gamma} P_{i}\right]^{\frac{1}{\gamma}}$ where $Q_{1}$ is the first dominant discharge, $Q_{\mathrm{i}}$ is the measured discharge process, and $P_{i}$ is the frequency of $Q_{i}$. The coefficient $\alpha$ is the power of the sediment concentration change with the discharge rate.

The coefficient $\gamma$ ranges from 1.5 to 4 . For alluvial rivers, $\gamma \approx 2$. It can be estimated by the relationship between sediment transport rate and discharge in reservoir channel (Han and $\mathrm{He}$ 1993). The coefficient $\gamma$ of Zhutuo to Chongqing reach is 2.51, the coefficient $\gamma$ of Chongqing to Cuntan reach is 2.57, the coefficient $\gamma$ of Cuntan to Qingxichang reach is 2.61, and the coefficient $\gamma$ of Qingxichang to Wanxian reach is 2.68 . 
Table 5 Calculation results of the first dominant discharge (Makayev method)

\begin{tabular}{lllll}
\hline Reach & Hydrologic station & \multicolumn{2}{c}{ Before impoundment } & \multicolumn{2}{c}{ After impoundment } \\
\cline { 5 - 5 } & & $1980-2002$ & $135 \mathrm{~m}$ & $145 \mathrm{~m}$ \\
\hline Variable backwater area & Zhutuo & 19,600 & 17,680 & 17,630 \\
& Cuntan & 21,200 & 18,130 & 18,090 \\
Perennial backwater area & Qingxichang & 20,590 & 26,150 & 31,980 \\
& Wanxian & 23,910 & 34,960 & 38,900 \\
\hline
\end{tabular}

The second dominant discharge refers to the flood discharge corresponding to half the accumulated amount of scouring and silting that occurs during the annual maximum flood. Han Qiwei explained that the second dominant discharge is equivalent to the bankfull discharge using the measured data of the cross section of the riverbed during the flood process (Han 2004).

The second dominant discharge determines the main channel section size of the river, reflecting the ability of floods to shape the channel. The formula for calculating the second dominant discharge is:

$\left.\sum_{Q=Q_{m}}^{Q=Q_{2}}\left(S_{i}-S_{*_{i}}\right) Q_{i} \Delta t_{i}\right) \sum_{Q=Q_{m}}^{Q=Q_{M}}\left(S_{i}-S_{*_{i}}\right) Q_{i} \Delta t_{i}=\frac{1}{2}$

where $Q_{2}$ is the second dominant discharge; $S_{i}$ is the measured sediment concentration process; and $S_{*_{I}}$ is the sediment transport capacity, which can be calculated using the empirical sediment transport formula (Zhao et al. 1998). $Q_{i}$ is the measured discharge process; $\Delta t_{i}$ is the duration of $Q_{i}$; and $Q_{m}$ and $Q_{M}$ are the minimum and maximum discharges, respectively, in the annual maximum flood process. According to Han Qiwei's empirical formula, the first and second dominant discharges at Zhutuo, Cuntan, Qingxichang, and Wanxian extended to the reservoir area.

Using Han Qiwei's empirical formula, the first and the second dominant discharges at Zhutuo, Cuntan, Qingxichang, and Wanxian reaches in the reservoir area could be calculated. It was determined that the first dominant discharges at Zhutuo and Cuntan in the upstream variable backwater areas before and after impoundment of the TGP were $11,210 \mathrm{~m}^{3} / \mathrm{s}$ and $10000 \mathrm{~m}^{3} / \mathrm{s}$ and $14,760 \mathrm{~m}^{3} / \mathrm{s}$ and $13330 \mathrm{~m}^{3} / \mathrm{s}$, respectively.
The first dominant discharges at Qingxichang and Wanxian in the perennial backwater areas before and after impoundment of the reservoir, as well as when the water levels were $135 \mathrm{~m}$ and $145 \mathrm{~m}$, were $16,780 \mathrm{~m}^{3} / \mathrm{s}, 21010 \mathrm{~m}^{3} / \mathrm{s}$, and $23720 \mathrm{~m}^{3} / \mathrm{s}$ and $17,580 \mathrm{~m}^{3} / \mathrm{s}, 21430 \mathrm{~m}^{3} / \mathrm{s}$, and $23970, \mathrm{~m}^{3} / \mathrm{s}$, respectively. The second dominant discharges at Zhutuo and Cuntan in the upstream variable backwater areas before and after impoundment of the TGP were $18,520 \mathrm{~m}^{3} / \mathrm{s}$ and $16510 \mathrm{~m}^{3} / \mathrm{s}$ and $24,370 \mathrm{~m}^{3} / \mathrm{s}$ and $22020 \mathrm{~m}^{3} / \mathrm{s}$, respectively. The second dominant discharges at Qingxichang and Wanxian in the perennial backwater areas before and after impoundment of the reservoir, as well as when the water levels were $135 \mathrm{~m}$ and $145 \mathrm{~m}$, were $27,650 \mathrm{~m}^{3} / \mathrm{s}, 34670 \mathrm{~m}^{3} / \mathrm{s}$, and $35770 \mathrm{~m}^{3} / \mathrm{s}$, and $28,960 \mathrm{~m}^{3} / \mathrm{s}, 35360 \mathrm{~m}^{3} / \mathrm{s}$, and $34870 \mathrm{~m}^{3} / \mathrm{s}$ (Tables 7, 8, and Fig. 7).

\section{Flow guarantee rate method}

In "Riverbed Evolution," Qian Ning points out that the evolution of a riverbed depends not only on the absolute water and sediment volume coming from upstream but also on their processes. Based on the statistics and analysis of multi-year data from the straight reach of the upper Yangtze River, Qian Ning determined that the dominant discharge is close to the flood peak discharge of 4 years $(P=25 \%)$ (Qian et al. 1987).

The P-III frequency distribution curve method (Eq. 3) is used to analyze the flow frequency:

$P(i)=\frac{m}{n+1}$

where $P(i)$ is the frequency of discharge greater than or equal to $i$ in the sample; $m$ is the number of discharges greater than
Table 6 Calculation results of the second dominant discharge (Makayev method)

\begin{tabular}{lllll}
\hline Reach & Hydrologic station & \multicolumn{2}{c}{ Before impoundment } & \multicolumn{2}{l}{ After impoundment } \\
\cline { 4 - 5 } & & $1980-2002$ & $135 \mathrm{~m}$ & $145 \mathrm{~m}$ \\
\hline Variable backwater area & Zhutuo & 25,640 & 21,630 & 21,890 \\
& Cuntan & 27,180 & 26,030 & 25,980 \\
Perennial backwater area & Qingxichang & 20,600 & 34,210 & 39,540 \\
& Wanxian & 33,960 & 41,150 & 44,900 \\
\hline
\end{tabular}


Table 7 Calculation results of the first dominant discharge (Han Qiwei empirical formula)

\begin{tabular}{llllr}
\hline Reach & Hydrologic station & \multicolumn{2}{c}{ Before impoundment } & \multicolumn{2}{c}{ After impoundment } \\
\cline { 4 - 5 } \cline { 4 - 5 } & & $1980-2002$ & $135 \mathrm{~m}$ & $145 \mathrm{~m}$ \\
\hline Variable backwater area & Zhutuo & 11,210 & 10,190 & 9920 \\
& Cuntan & 14,760 & 13,290 & 13,370 \\
Perennial backwater area & Qingxichang & 16,780 & 21,010 & 23,720 \\
& Wanxian & 17,580 & 21,430 & 23,970 \\
\hline
\end{tabular}

or equal to $i$ in the sample; and $n$ is the total capacity of the sample. The flood discharges $(P=25 \%)$ at Zhutuo and Cuntan before and after the Three Gorges impoundment were $13,500 \mathrm{~m}^{3} / \mathrm{s}$ and $11700 \mathrm{~m}^{3} / \mathrm{s}$ and $17,120 \mathrm{~m}^{3} / \mathrm{s}$ and $13100 \mathrm{~m}^{3} / \mathrm{s}$, respectively, in the variable backwater area of the upper Yangtze River.

The flood discharges $(P=25 \%)$ at Qingxichang and Wanxian before and after impoundment of the reservoir, as well as when the water levels were $135 \mathrm{~m}$ and $145 \mathrm{~m}$, were $19,360 \mathrm{~m}^{3} / \mathrm{s}, 26300 \mathrm{~m}^{3} / \mathrm{s}$, and $27360 \mathrm{~m}^{3} / \mathrm{s}$ and $19,730 \mathrm{~m}^{3} / \mathrm{s}$, $26430 \mathrm{~m}^{3} / \mathrm{s}$, and $27650 \mathrm{~m}^{3} / \mathrm{s}$, respectively, in perennial backwater areas (Table 9).

\section{Analysis of results and comparison of methods}

From the calculation results yielded by the above three methods, it can be concluded that the dominant discharge in the reservoir channel of the upper Yangtze River basically increases along the river from Zhutuo to Wanxian. Temporally, after the TGR became operational, the dominant discharge in the reservoir channel decreased in the variable backwater area, while increasing in the perennial backwater area. From the dam site to the Zhutuo station, the dominant discharge in the reservoir channel decreases gradually along the river. After reservoir impoundment, with the rise of water level in front of the dam, the dominant discharge in the reservoir channel remained basically unchanged in the variable backwater area, while increasing in the perennial backwater area.

Since the flow guarantee rate method relies on observations to select the flood discharge of a certain return period as the dominant discharge, it does not take riverbed erosion and deposition into account, resulting in error. In addition, the terrain surrounding a river in a mountainous area is variable, resulting in different boundary conditions. Thus, the empirical formula will also have errors when applied to specific river sections.

In the Han Qiwei empirical formula, the first dominant discharge represents the equivalent discharge of sediment transport capacity during the process of variable discharge, guarantees the flow for the longitudinal equilibrium of the river channel, and also shapes the flow in the longitudinal section of the riverbed. The second dominant discharge shapes the cross section of the riverbed. Although the reservoir bedforming effect is fully revealed from the perspective of sediment transport balance, an empirical formula is used for the case of large variations of topography and river facies coefficients in the TGR area, since a fixed, as opposed to variable, discharge process is employed for the same conditions of slope, roughness, and river facies coefficients. This results in application errors.

The Makayev method considers the shear stress effect of discharge on a riverbed from the aspects of bed-forming intensity as well as duration. It not only considers water and sediment processes during the entire calculation period but also the boundary conditions of the riverbed (the relationship between river alluviation, water level, and specific drop). This method takes the effects of both discharge magnitude (i.e., strength) and discharge duration into account. The sediment transport capacity indirectly reflects changes in the erosion and deposition of the riverbed, which has a strong theoretical basis and a clear physical meaning.

The calculation results show that the reservoir channel dominant discharges determined by the flow guarantee rate method and Han Qiwei empirical formula were less than the dominant discharge value calculated using the Makayev
Table 8 Calculation results of the second dominant discharge (Han Qiwei empirical formula)

\begin{tabular}{lllll}
\hline Reach & Hydrologic station & \multicolumn{2}{c}{ Before impoundment } & \multicolumn{2}{c}{ After impoundment } \\
\cline { 4 - 5 } & & $1980-2002$ & $135 \mathrm{~m}$ & $145 \mathrm{~m}$ \\
\hline Variable backwater area & Zhutuo & 18,520 & 16,860 & 16,390 \\
& Cuntan & 24,370 & 21,960 & 22,040 \\
Perennial backwater area & Qingxichang & 27,650 & 34,670 & 35,770 \\
& Wanxian & 28,960 & 35,360 & 34,870 \\
\hline
\end{tabular}



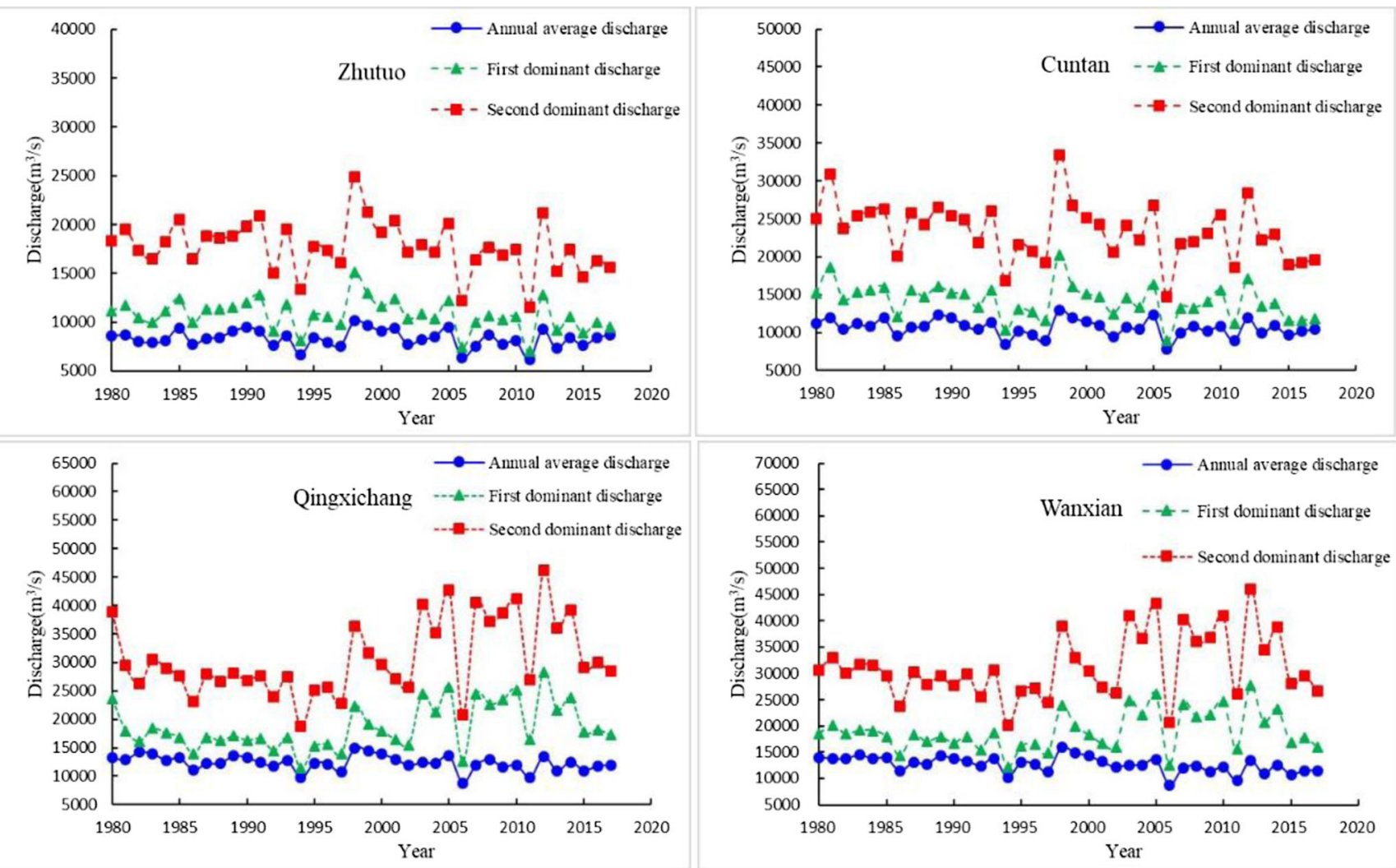

Fig. 7 Annual average discharge and dominant discharge in reservoir channel of the TGR (Makayev method)

method. This is due to the over-emphasis on empirical data in the flow guarantee rate method and the lack of topographic boundary conditions in the Han Qiwei empirical formula.

Therefore, the Makayev method is more reliable for calculating the dominant discharge of the TGR channel. It uses the capacity and duration of flow and sediment transport in order to comprehensively reflect the bed-forming effect, which is a more realistic approach than the other methods.

\section{Factors affecting dominant discharge}

By definition, the dominant discharge is the characteristic discharge reflecting the capacity of sediment transport and bedforming for given water and sediment processes. It is primarily determined by the incoming water and sediment processes. This study mainly analyzed the influential factors of the average annual discharge, the average flood season discharge, and the peak flood discharge.

The Makayev method was used to calculate the dominant discharge at the Qingxichang station in the perennial reach of the reservoir area from 1980 to 2017 (Fig. 8). This method demonstrated that the annual average discharge, the flood season average discharge, and the flood peak discharge at the Qingxichang station decreased slightly after the impoundment of the TGR, although the dominant discharge increased.

Before the TGR became operational, the correlations between the dominant discharge and the annual average discharge, the flood peak discharge, and the flood season
Table 9 Calculation results of 4 year flood peak discharge (flow guarantee rate method)

\begin{tabular}{lllll}
\hline Reach & Hydrologic station & \multicolumn{2}{c}{ Before impoundment } & \multicolumn{2}{c}{ After impoundment } \\
\cline { 4 - 5 } & & $1980-2002$ & $135 \mathrm{~m}$ & $145 \mathrm{~m}$ \\
\hline Variable backwater area & Zhutuo & 13,500 & 11,700 & 11,700 \\
& Cuntan & 17,120 & 13,100 & 13,100 \\
Perennial backwater area & Qingxichang & 19,360 & 26,300 & 27,360 \\
& Wanxian & 19,730 & 26,430 & 27,650 \\
\hline
\end{tabular}


Fig. 8 Characteristic discharge at Qingxichang station from 1980 to 2017 (Makayev method)

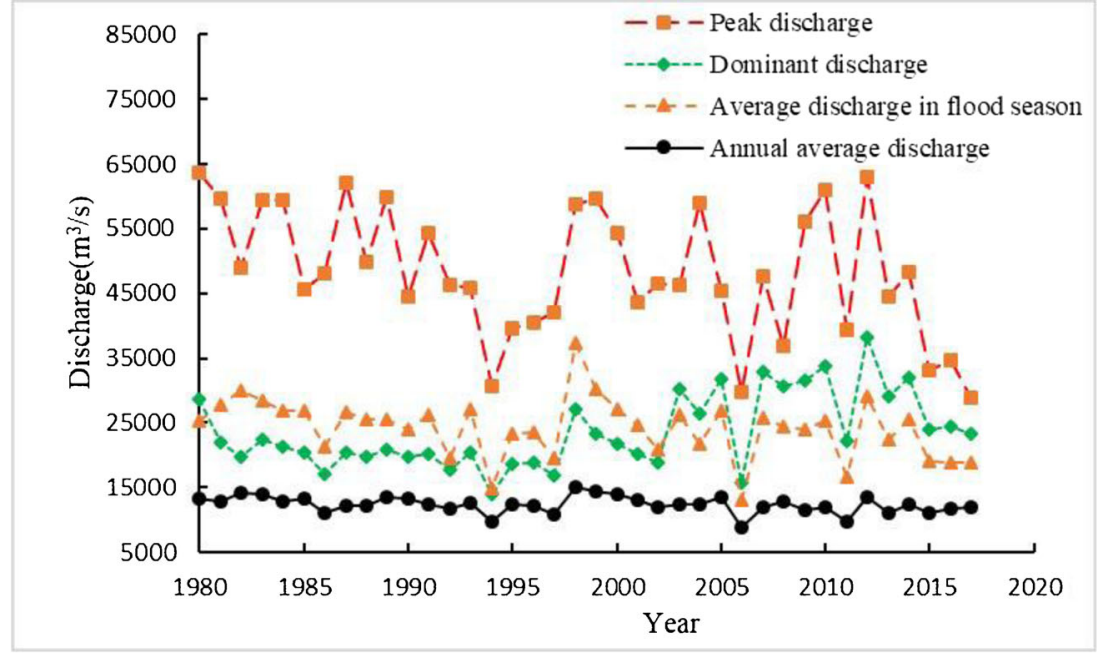

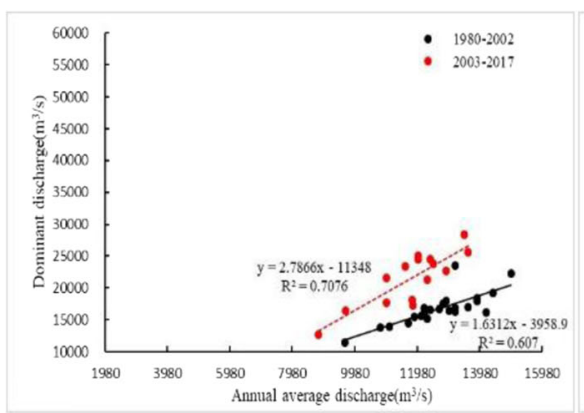
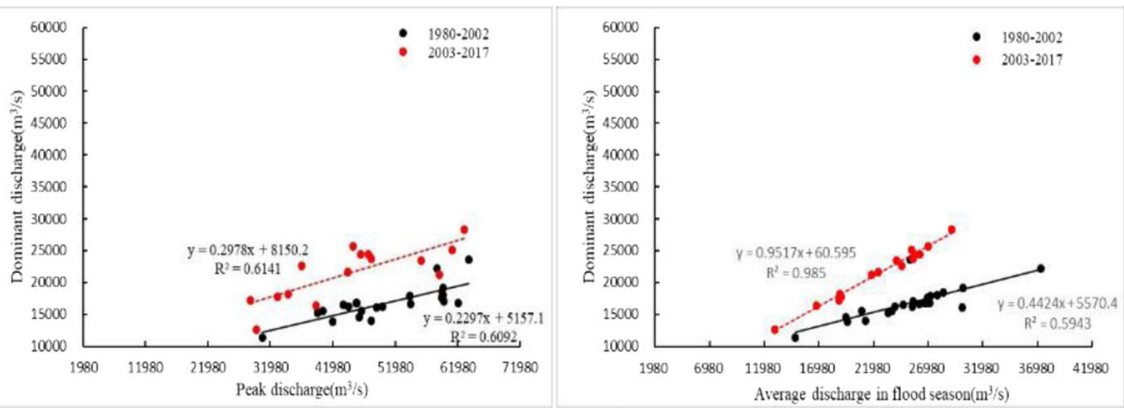

Fig. 9 Response relationship between dominant discharge and other characteristic discharge before and after impoundment of the TGR

average discharge at the Qingxichang station were 0.607, 0.609 , and 0.594 , respectively. After impoundment, these correlations were $0.708,0.614$, and 0.985 , respectively (Fig. 9). The correlation between the dominant discharge and the flood season average discharge was very apparent, further confirming that the bed-forming period of the reservoir area is the flood season.

\section{Conclusions}

(1) The Makayev method reflects the combined effects of sediment transport capacity and discharge duration on the fundamental shaping of riverbeds, including the consideration of riverbed erosion and sedimentation changes. The physical meaning is clear, the theory is superior to that of the other methods, and the calculation results are relatively reasonable.

(2) After TGP impoundment, the dominant discharge in the variable backwater area decreased, while increasing in the perennial backwater area. After impoundment of the Three Gorges, with the rising of the water level in front of the dam, the dominant discharge in the variable backwater area remained basically unchanged, while increasing in the perennial backwater area.

(3) The dominant discharge of the TGR is affected by incoming water processes as well as the reservoir operation mode. It correlates well with the average annual discharge, the average flood season discharge, and the peak flood discharge. Before impoundment, the correlation between the dominant discharge and these three parameters is high. After impoundment, the correlation between the dominant discharge and the average flood season discharge is more apparent, further confirming that the bed-forming period of the reservoir area is the flood season.

Acknowledgments We are grateful to the Changjiang Water Resources Commission (CWRC) for the access to the valuable data sets. The authors would like to thank LetPub (www.letpub. com) for its linguistic assistance during the preparation of this manuscript. We gratefully acknowledge the anonymous reviewers and editors for their reviews and suggestions.

Funding information This study was supported by the National Key R\&D Program of China (Grant No. 2016YFC0402302 and No. 2017YFC0405202). 
Open Access This article is distributed under the terms of the Creative Commons Attribution 4.0 International License (http:// creativecommons.org/licenses/by/4.0/), which permits unrestricted use, distribution, and reproduction in any medium, provided you give appropriate credit to the original author(s) and the source, provide a link to the Creative Commons license, and indicate if changes were made.

\section{References}

Chen X, Han Q, Fang C (2007) Variation of dominant discharge in lower Yellow River and its influence on river channel. J Hydraul Eng 38(1):15-22

Chu WQ, Li YL, Xie L (2015) Calculation of dominant discharge of Chongqing Urban Reach in Yangtze River main stream. J Chongqing Jiaotong Univ (Nat Sci) 2015(2):69-71 (in Chinese)

Colosimo C, Copertino VA, Vehri M (1988) Friction factor evaluation on gravel-bed rivers. J Hydraul Eng 114(8):861-869

Ferro V, Porto P (2012) Identifying a dominant discharge for natural rivers in southern Italy. Geomorphology 139(2):313-321

Hadadin N (2017) Variation in hydraulic geometry for stable versus incised streams in the Yazoo River basin-USA. Int J Sediment Res 32(1):121-126

Han Q (2004) Some rules of sediment transportation and depositionscouring in the lower Yellow River. J Sediment Res 2004(03):1-13

Han Q, He M (1993) Process of the channel formation in long-term operation reservoir. J Sediment Res 1993(03):1-21
Huang, Renyong (2016) Study on the sediment transport and sediment operation of cascade reservoirs in the upper Changjiang river. WuHan University

Ji ZW, Hu CH, Yan Y et al (1994) Dominant discharge on heavy sediment-laden river. Adv Water Sci 5(3):229-234 (in Chinese)

Qian N, Zhang R, Zhou Z (1987) Riverbed evolution. Science Press, Beijing (in Chinese)

Sun D, Wang Q et al (2013) Determination of dominant discharge of the lower Yellow River based on coefficient frequencies of flowsediment relationship. J Hydroelectr Eng 32(01):150-155

Wolman MG, Miller JP (1960) Magnitude and frequency of forces in geomorphic processes. J Geol 68:54-74

Xie JH (2013) Riverbed evolution and renovation. Wuhan University Press, Wuhan (in Chinese)

Xu LL, Zhen F, Jiang HY (2017) Calculation of dominant discharge with its characteristics in the river channel section of the lower Yangtze River at Zhenjiang. J Glaciol Geocryol 2017(2):416-420 (in Chinese)

Yan JB, Tang QX, Zou T (2014) Variation of dominant discharge and sediment-carrying capacity of flow in the downstream of Three Gorges Reservoir. J Yangtze River Sci Res Instit 31(2):114-118 (in Chinese)

Zhang W, Gao Y, Xu Q et al (2018) Changes in dominant discharge and their influential factors in the middle and lower reaches of Yangtze River after the Three Gorges Dam impoundment. Adv Water Sci 29(03):331-338

Zhao Y, Zhou W, Fei J et al (1998) Basic development law and prospect prediction of the lower reaches of the Yellow River. The Yellow River Water Conservancy Press, Zhengzhou 